\title{
Aerobic midgut microbiota of sand fly vectors of zoonotic visceral leishmaniasis from northern Iran, a step toward finding potential paratransgenic candidates
}

Fateh Karimian ${ }^{1}$, Hassan Vatandoost ${ }^{1}$, Yavar Rassi ${ }^{1}$, Naseh Maleki-Ravasan², Mehdi Mohebali, Mohammad Hasan Shirazi ${ }^{4}$, Mona Koosha ${ }^{1}$, Nayyereh Choubdar ${ }^{1}$ and Mohammad Ali Oshaghi ${ }^{{ }^{*}}$ (i)

\begin{abstract}
Background: Leishmaniasis is caused by Leishmania parasites and is transmitted to humans through the bite of infected sand flies. Development of Leishmania to infective metacyclic promastigotes occurs within the sand fly gut where the gut microbiota influences development of the parasite. Paratransgenesis is a new control method in which symbiotic bacteria are isolated, transformed and reintroduced into the gut through their diet to express anti-parasitic molecules. In the present study, the midgut microbiota of three sand fly species from a steppe and a mountainous region of northern Iran, where zoonotic visceral leishmaniasis (ZVL) is endemic, was investigated.

Methods: Briefly, adult female sand flies was collected during summer 2015 and, after dissection, the bacterial composition of the guts were analyzed using a culture-dependent method. Bacterial DNA from purified colonies was extracted to amplify the 165 rRNA gene which was then sequenced.

Results: Three ZVL sand fly vectors including Phlebotomus major, P. kandelakii and P. halepensis were found in the highlighted regions. In total, 39 distinct aerobic bacterial species were found in the sand fly midguts. The sand fly microbiota was dominated by Proteobacteria (56.4\%) and Firmicutes (43.6\%). Bacterial richness was significantly higher in the steppe region than in the mountainous region (32 vs 7 species). Phlebotomus kandelakii, the most important ZVL vector in the study area, had the highest bacterial richness among the three species. Bacillus subtilis and Pantoea agglomerans were isolated from the guts of the sand flies; these are already used for the paratransgenesis of sand flies and mosquitoes, respectively.

Conclusions: The existence of B. subtilis and P. agglomerans in the ZVL vectors and other sand fly species studied so far suggests that these two bacterial species are potential candidates for paratransgenic approach to prevent ZVL transmission. Further research needs to test the possible relationship between the gut microbiome richness and the vector competence of the $\mathrm{ZVL}$ vectors.
\end{abstract}

Keywords: Sand fly, Microbiota, Paratransgenesis, Leishmaniasis, Iran

\footnotetext{
* Correspondence: moshaghi@sina.tums.ac.ir

${ }^{1}$ Department of Medical Entomology and Vector Control, School of Public

Health, Tehran University of Medical Sciences (TUMS), Tehran, Iran

Full list of author information is available at the end of the article
}

(c) The Author(s). 2019 Open Access This article is distributed under the terms of the Creative Commons Attribution 4.0 International License (http://creativecommons.org/licenses/by/4.0/), which permits unrestricted use, distribution, and reproduction in any medium, provided you give appropriate credit to the original author(s) and the source, provide a link to the Creative Commons license, and indicate if changes were made. The Creative Commons Public Domain Dedication waiver (http://creativecommons.org/publicdomain/zero/1.0/) applies to the data made available in this article, unless otherwise stated. 


\section{Background}

Sand flies are the major vectors of various Leishmania spp., the etiological parasitic agents of leishmaniasis, a neglected tropical disease (NTD). Several clinical forms of leishmaniasis have been described including cutaneous, mucocutaneous and visceral (also known as kala-azar) forms [1, 2]. Approximately 350 million people are at risk of leishmaniasis, with nearly 12 million people in tropical, subtropical and Mediterranean regions affected by the disease. Visceral leishmaniasis (VL) is endemic in more than 65 countries and caused by various Leishmania species, L. donovani and L. infantum having a major incidence. The case-fatality rate of VL is about $10 \%$ of an estimated 200,000-400,000 cases annually [3]. In Iran, zoonotic visceral leshmaniasis (ZVL) is caused mainly by $L$. infatum and is endemic in the northwestern and southern regions with 100-300 new cases every year [4-6]. More than 30\% of ZVL cases have been reported in northwestern areas. The disease is highly prevalent $(>90 \%)$ in children less than ten years-old where domestic dogs and other canines are reservoir hosts of the disease [5-7]. Several sand fly species, including Phlebotomus perfiliewi transcaucasicus, $P$. kandelakii and P. tobbi in northeastern and northwestern and P. major (s.l.) (P. neglectus), P. keshishiani and $P$. alexandri in southern areas of the country, were incriminated as possible vectors of ZVL [8-13]. The lack of an effective vaccine against leishmaniasis, narrow ranges of effectiveness and unfavorable side effects of available drugs, and development of drug resistance in the parasite highlight the need for novel approaches to control vector transmission of L. infantum [14].

Paratransgenesis is an alternative control strategy, where commensal or symbiont bacteria found in insect vector/s is engineered to inhibit pathogen transmission [15-17]. The principal and essential step in paratransgenesis is the identification of suitable bacterium/bacteria in the vector. The characteristics required for a candidate include being non-pathogenic to human and non-target animals, dominancy within the vector-associated microflora, cultivability in cell-free media, malleable to transformation with foreign DNA, and having a wide distribution [18]. Gut microbial communities, including bacterial species, have been investigated in various insects including blood sucking bugs [19], tsetse flies [20], mosquitoes [21-24] American cockroaches [25] and sand flies [26-28]. So far, researchers have nominated a few bacterial candidates for a paratransgenic approach to block Leishmania transmission in sand fly vectors including Bacillus megaterium, Brevibacterium linens and Enterobacter cloacae [16, 26, 28].

The digestive tract of Phlebotomus spp. is the main colonizing site of various microorganisms including bacteria. Sand flies acquire bacteria from food and the soil in which they breed at the larval stage and via polluted sugar meals derived from plant leaves and fruits or aphid honeydew at the adult stage [2]. The skin of sand fly hosts (e.g. mammals and reptiles) is another source of bacteria for female insects when ingesting blood meals. However, these blood meals are usually sterile [29]. Although the midgut microbiota of insects is apparently a function of the host, feeding behavior and environment factors, the effects of these factors on the composition and diversity of sand fly gut microbiota are commonly indefinite. Some of these factors include genetics and physicochemical parameters of insect, larval habitats and vertebrate hosts, climate, geographical features, and soil and plant attributes [30-35]. The aim of this study was to assess the composition of aerobic gut bacterial communities in the kala-azar vector Phlebotomus species from two different geographical regions (steppe and mountainous) in north of Iran as well as the community composition between various populations of an identical species. This information is important for the better understanding of symbiotic or commensal relationships between the bacteria and sand flies, mechanisms that determine gut microbiota composition and introduction of a potential candidate for a paratransgenesis approach against leishmaniasis in the study areas.

\section{Methods}

\section{Study area}

The present study was carried out in two endemic foci of zoonotic visceral leishmaniasis in northeastern (North Khorasan Province) and northwestern (Ardabil Province) of Iran (Fig. 1). Up to 2012, a total of about 900 and 164 (44.6 and $8.2 \%$ of total cases in the country) VL cases have been reported from northwestern in northeastern regions of the country, respectively $[4,36]$. North Khorasan Province $\left(36^{\circ}\right.$ $37^{\prime}-38^{\circ} 17^{\prime} \mathrm{N}, 55^{\circ} 53^{\prime}-58^{\circ} 20^{\prime} \mathrm{E}$ ) is a mountainous region located in northeastern Iran, 1070 meters above sea level and with an area of more than $28,400 \mathrm{~km}^{2}$. The weather is hot (up to $32.4{ }^{\circ} \mathrm{C}$ ) in summer and cold (below $-3.4{ }^{\circ} \mathrm{C}$ ) in winter, with an average annual temperature of $13.2{ }^{\circ} \mathrm{C}$. This region is a desert and mountainous area and receives less than $250 \mathrm{~mm}$ rainfall annually. Ardabil Province $\left(37^{\circ} 04^{\prime}-39^{\circ} 65^{\prime} \mathrm{N}, 47^{\circ} 40^{\prime}-\right.$ $\left.48^{\circ} 71^{\prime} \mathrm{E}\right)$ is a steppe region located 1490 meters above sea level with an area of more than 17,800 square $\mathrm{km} 2$. The weather is hot (up to $40{ }^{\circ} \mathrm{C}$ ) in summer and cold (below -20 ${ }^{\circ} \mathrm{C}$ ) in winter with an average annual temperature of $9.5^{\circ} \mathrm{C}$. The warm season is short (mid-May to mid-September). The annual rainfall is approximately $325 \mathrm{~mm}$ and the climate is warm and temperate, considered to be a local steppe climate. Details of the climate data during sample collection are shown in Table 1.

\section{Sand fly midgut collection}

To study the aerobic microbiota of the sand fly gut, wild sand flies were collected from the study areas using 


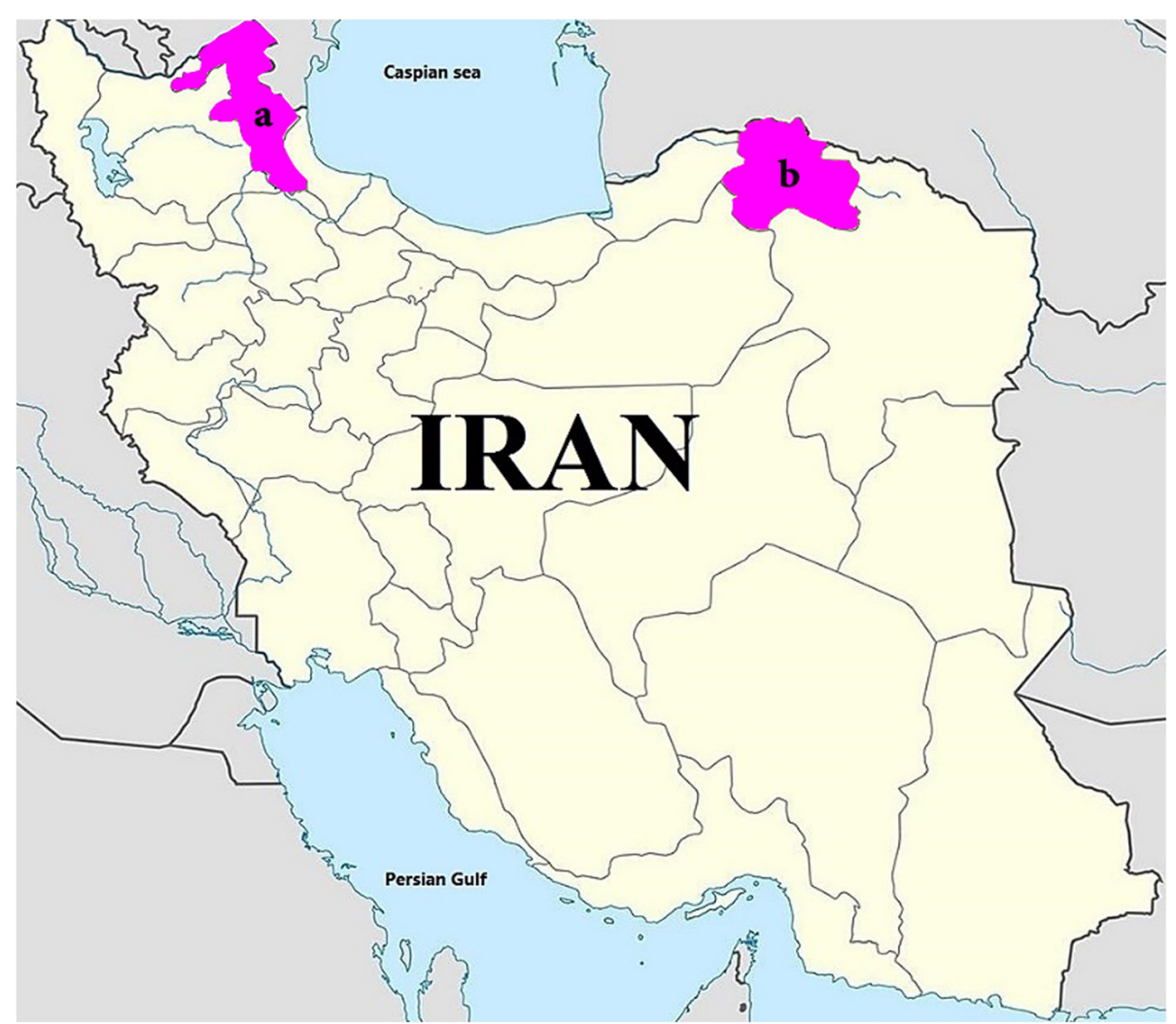

Fig. 1 Map of two endemic visceral leishmaniasis $(V L)$ foci in northwest and northeast of Iran where sand flies were collected. a Ardabil Province. b North Khorasan Province

various methods including CDC light traps, car traps and aspirators during 2015. Live sand flies were immediately transferred to the Insect Molecular Biology Laboratory, Department of Medical Entomology and Vector Control, School of Public Health, Tehran University of Medical Science, Tehran, Iran, in cold chain condition.

\section{Isolation of bacteria}

Female sand fly specimens $(n=117)$ were separated from male specimens $(n=324)$ and used for bacterial isolation. Female specimens were immediately microdissected individually under a microbiological safety cabinet on a sterile glass slide. First, specimens were surface sterilized using $70 \%$ ethanol for 3-5 min and then the gut of each specimen was micro-dissected and homogenized by shaking in a sterile tube containing glass beads. This was transferred to test screw tubes containing $5 \mathrm{ml}$ of brain heart infusions (BHI) broth and incubated at 37 ${ }^{\circ} \mathrm{C}$ for $24-48 \mathrm{~h}$ in aerobic conditions. Cloudy test tubes were considered as positive specimens. The grown bacteria were serially diluted or streaked on BHI agar plates and subcultured several times on the agar plates in the same conditions to achieve individual purified colonies. The remainder of the dissected insect body was mounted on a slide for morphological identification. Following species identification, microbiota definition was carried out only for specimens corresponding to known $\mathrm{VL}$ vectors. Test tubes containing BHI broth were opened near the dissection area under sterile conditions during the micro-dissection processes. Individual colonies were selected and used for further molecular identification. The richness of each bacterial family was calculated based on the total number of $16 S$ sequences.

\section{5 rRNA gene amplification}

DNA extraction from individual colonies was carried out using the phenol/chloroform DNA extraction method as previously described by Maleki-Ravasan et al. [26].

Table 1 Climate data during the sample collection in the study areas

\begin{tabular}{llllllll}
\hline Location & Coordinates & Date & Season & $\mathrm{T}\left({ }^{\circ} \mathrm{C}\right)$ & Mean RH $(\%)$ & Rain $(\mathrm{mm})$ & Mean wind speed $(\mathrm{km} / \mathrm{h})$ \\
\hline Meshkinshahr & $37^{\circ} 04^{\prime}-39^{\circ} 65^{\prime} \mathrm{N}, 47^{\circ} 40^{\prime}-48^{\circ} 71^{\prime} \mathrm{E}$ & 2015 & Late spring-early summer & $7-31$ & 59.31 & 0 & 18 \\
Bojnurd & $36^{\circ} 37^{\prime}-38^{\circ} 17^{\prime} \mathrm{N}, 55^{\circ} 53^{\prime}-58^{\circ} 20^{\prime} \mathrm{E}$ & 2015 & Late spring-early summer & $12-39$ & 47.2 & 0 & 9 \\
\hline
\end{tabular}


Nearly 1500 bp of the bacterial $16 S$ rRNA gene including the less variable V1-V2 and the highly variable V3-V5 regions were amplified using the universal primers $16 \mathrm{suF}$ (5'-GAG TTT GAT CCT GGC TCA G-3') and 16suR (5'-GTT ACC TTG TTA CGA CTT-3') [37]. Polymerase chain reaction (PCR) amplification was carried out using a Maxime PCR PreMix Kit (i-Taq) in $20 \mu \mathrm{l}$ reaction mixtures containing $1 \mu \mathrm{l}$ of each primer with $10 \mu \mathrm{M}$ concentration and 1-2 $\mu \mathrm{l}(\sim 0.1 \mu \mathrm{g})$ of extracted genomic DNA. $\mathrm{BHI}$ agar media and $\mathrm{ddH}_{2} \mathrm{O}$ were used as negative controls. The thermal cycler conditions were set as follows: an initial denaturation at $94{ }^{\circ} \mathrm{C}$ for $10 \mathrm{~min}$, followed by 35 cycles of denaturation at $95{ }^{\circ} \mathrm{C}$ for $30 \mathrm{~s}$, annealing at $57.5^{\circ} \mathrm{C}$ for $40 \mathrm{~s}$ and extension at $72{ }^{\circ} \mathrm{C}$ for $30 \mathrm{~s}$. Final extension was at $72{ }^{\circ} \mathrm{C}$ for $8 \mathrm{~min}$. The PCR products were visualized on a $1 \%$ agarose gel containing ethidium bromide using a UV transilluminator. QIAquick PCR Purification Kit (Qiagen, Hilden, Germany) was used for purification of the PCR products before sequencing.

\section{$16 \mathrm{~S}$ rRNA gene sequencing and analysis}

First, $16 S$ rRNA amplicons were amplified using each forward or reverse primer and then sequenced using the Sanger method (Macrogen, Seoul, S. Korea). To compare these sequences with those available in ribosomal databases, nine databases of prokaryotic $16 S$ rRNA gene were used, namely NCBI (nucleotide collection; http:// blast.ncbi.nlm.nih.gov/Blast.cgi), EMBL (http://www.ebi.ac.uk/ena), RDP (http://rdp.cme.msu.edu/seqmatch/ seqmatch_intro.jsp), EzTaxon-e (http://eztaxon-e.ezbiocloud.net), Greengenes (http://greengenes.lbl.gov/cgibin/nph-index.cgi), DDBJ (http://blast.ddbj.nig.ac.jp/ ?lang=en), leBIBI (http://umr5558-sud-str1.univ-lyon1.fr /lebibi/lebibi.cgi) and Blast2Tree (http://bioinfo.unice.fr/ blast) $[38,39]$. Sequence homology with available data was assessed based on the number and quality of nucleotides of the sequence reads using appropriate features of the data such as cultivable and/or non-cultivable and type and/or non-type specimens. The sequences were assigned at the species level based on either the most common nomenclature within the results of the nine databases or the highest similarity rate. Nucleotide homology > 95 and $98 \%$ were considered as lower thresholds at genus and species levels, respectively (https://rdp.cme.msu.edu).
The partial $16 \mathrm{~S}$ rDNA consensus sequences obtained in this study were annotated in the GenBank database using the $16 S$ ribosomal RNA database (https://submit.ncbi.nlm. nih.gov/subs/genbank). Species assignation of the symbiont bacteria was verified by phylogenetic analysis using $16 S$ rRNA gene sequences based on the neighbor-joining algorithm of MEGA7 Software. Cytoscape Software (http://www.cytoscape.org), as a tool for visualizing complex networks among data, was used to visualize bacterial richness and shared bacteria in the three sand fly species through the network analysis [40]. Data, as CYS files containing vertices or nodes (representing symbiont bacteria and sand fly hosts) and edges (representing links), were submitted to Cytoscape software v.3.5.1. Bacterial and host nodes as well as geographical region links were colored for the better demonstration of their interaction. GraphPad Prism software v.5.00 for Windows (GraphPad, San Diego, USA) and Student's t-test embedded in the software was used for graphical representation and statistical analysis, respectively.

\section{Results}

In total, 1772 sand flies comprising 1565 (88.3\%) Phlebotomus and 207 (11.7\%) Sergentomyia specimens were collected from the study areas. The Phlebotomus species included ZVL vectors $P$. major, $P$. kandelakii and $P$. halepensis, and cutaneous leishmaniasis $(\mathrm{CL})$ vectors $P$. sergenti and $P$. papatasi. Approximately 64.5\% $(n=$ 1142 ) of the specimens were male. After exclusion of Sergentomyia spp., the CL vectors, dead females and male specimens, 117 live female ZVL phlebotomine sand flies comprising 48 P. kandelakii, 51 P. major and $18 P$. halepensis specimens were processed individually for their midgut bacterial composition. A total of 39 independent bacterial colonies or OTUs across six families was obtained from the midgut of the three field-collected sand fly species (Table 2).

The phylogenetic relationships of the bacteria and their corresponding taxonomic status at family level, in addition to their host and collection sites are shown in Fig. 2. Members of Bacillaceae, Ralstoniaceae and Aeromonadaceae were reported only in the steppe region (Bojnurd). Furthermore, results showed that bacterial taxonomic richness of the steppe region sand flies was

Table 2 Details of bacterial richness in the midgut of three sand fly species from steppe (Bojnurd) and mountainous (Meshkinshahr) regions in northeastern Iran

\begin{tabular}{|c|c|c|c|c|c|c|c|c|c|c|c|c|}
\hline \multirow[t]{2}{*}{ Location } & \multicolumn{3}{|c|}{ P. major } & \multicolumn{3}{|c|}{ P. kandelakii } & \multicolumn{3}{|c|}{ P. halepensis } & \multicolumn{3}{|c|}{ Total } \\
\hline & $n$ & BS & BSPP & $n$ & BS & BSPP & $n$ & BS & BSPP & $n$ & BS & BSPP \\
\hline Bojnurd & 33 & 18 & 12 & 36 & 16 & 12 & 18 & 8 & 8 & 87 & 42 & 32 \\
\hline Meshkinshahr & 18 & 3 & 2 & 12 & 6 & 5 & 0 & 0 & 0 & 30 & 9 & 7 \\
\hline Total & 51 & 21 & 14 & 48 & 22 & 17 & 18 & 8 & 8 & 117 & 51 & 39 \\
\hline
\end{tabular}

Abbreviations: $n$ number of sand flies, BS number of bacterial sequences, BSPP number of bacterial species 


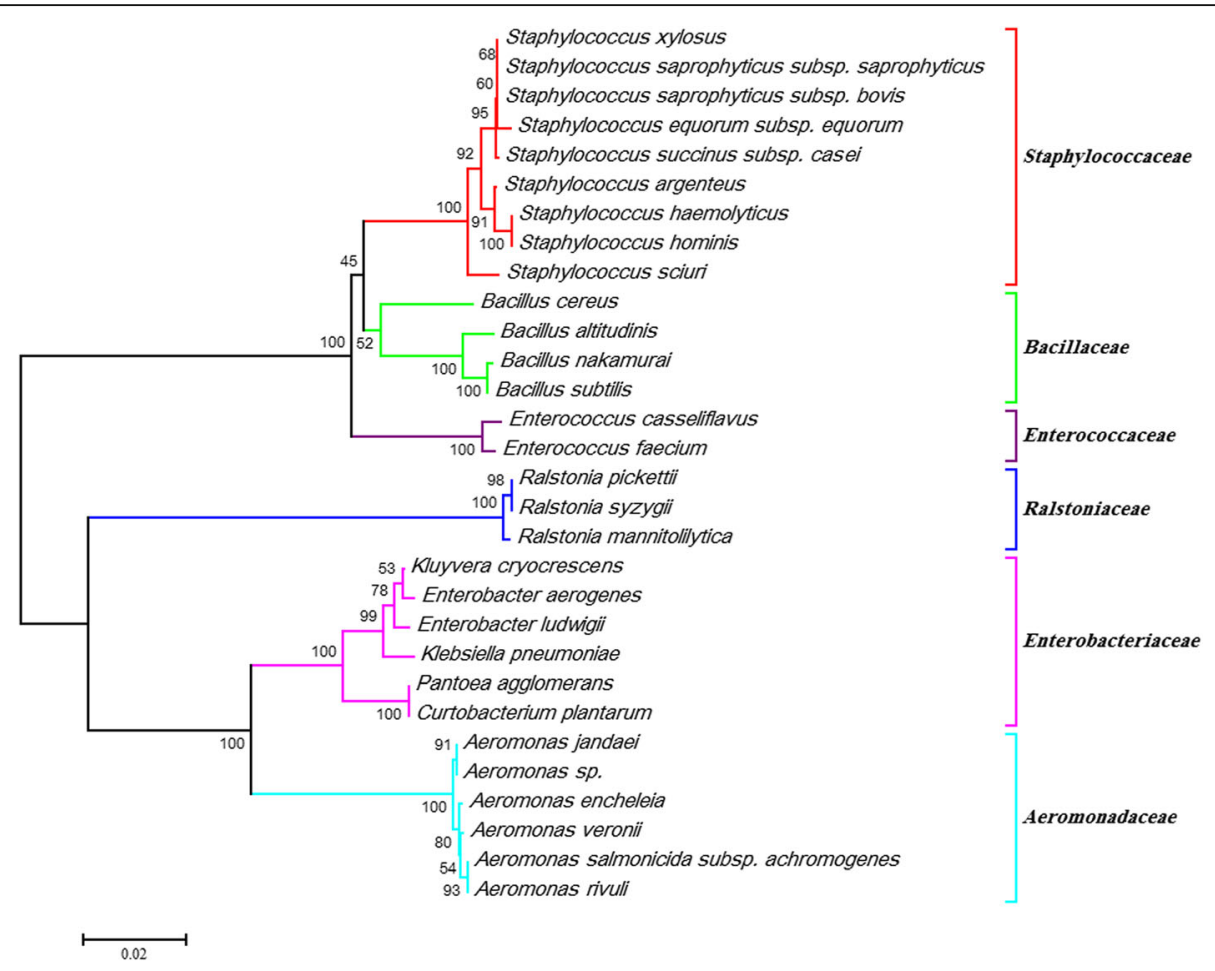

Fig. 2 Phylogenetic analysis of gut microbiota isolated from P. kandelakii (k), P. major $(\mathrm{m})$ and P. halepensis (h) sand flies verified by 980 bp of 165 rRNA gene sequences. The sequences were aligned using Clustal Omega Software. The phylogenetic tree was constructed based on the neighbor-joining algorithm using MEGA7 software. Each bacterial family in the phylogenetic tree is represented by a separate colored line. Bootstrap values are shown at nodes. Scale of the genetic distance is shown underneath. Abbreviations: B, Bojnurd; M, Meshkinshahr

greater (32 vs 7 species) than that of moderate mountainous region. Tables 3 and 4 show details of 39 isolated bacteria from the midgut of P. major, P. kandelakii and P. halepensis from the study areas. Phlebotomus kandelakii midgut with 17 bacterial species or OTUs had the greatest bacterial richness among the three host species (Table 2 and Fig. 2). Phlebotomus major and P. halepensis harbored 14 and 8 bacterial species, respectively (Table 2 and Fig. 2). Ralstonia pickettii was the only shared bacteria found in all the three sand fly species in the steppe region (Fig. 3). There were six, three and one shared bacterial species between $P$. major-P. kandelakii, $P$. major-P. halepensis and $P$. kandelakii-P. halepensis, respectively, in the steppe region (Tables 3 and 4 and Figs. 3 and 4). No shared bacterium was reported between sand fly guts in the mountainous study area. In total, nearly $80 \%$ of the bacteria were observed in individual species only.

The bacterial colonies isolated from sand fly midguts belonged to two phyla: Proteobacteria (56.41\%) and Firmicutes (43.59\%) across six families (Fig. 5). Based on oxygen demands, about 87.2 and $12.8 \%$ of the bacteria were assigned as aerobes and facultative anaerobes, respectively. The genus Staphylococcus (26.66\%) and the family Enterobacteriaceae (27.27\%) had the highest abundances in the sand fly species.
Except for $P$. major, there was notable differences in taxonomic composition between the bacterial microbiota among allopatric sand fly species (occurring in separate non-overlapping geographical areas), and sympatric (occurring within the same or overlapping geographical areas) sand flies (Fig. 6). In the steppe region, for P. kandelakii, the midgut bacterial composition was Proteobacteria (33.33\%) and Firmicutes (66.67\%), and for $P$. halepensis the midgut bacterial composition was Proteobacteria $(87.50 \%)$ and Firmicutes $(12.50 \%)$. In the mountainous region, for P. kandelakii, the midgut bacterial composition was Proteobacteria (83.34\%) and Firmicutes (16.66 \%) (Fig. 6). For P.major, the midgut bacterial composition was Proteobacteria (50\%) and Firmicutes (50\%) in both regions.

\section{Discussion}

In the present study, gut aerobic microbiota of three different sand fly species was assessed using the culture dependent method and $16 \mathrm{~S}$ rRNA gene sequencing. Results showed that gut microbiota of these insects were dominated by Proteobacteria (56.41\%) and Firmicutes (43.59\%), in agreement with previous studies using either culture-dependent or independent methods (next-generation sequencing, NGS) showing that these two phyla were the predominant phyla in various groups of insects 
Table 3 Details of the bacteria isolated from the midgut of sand flies captured in the steppe region (Bojnurd) of northeastern Iran

\begin{tabular}{|c|c|c|c|c|c|c|}
\hline \multirow[t]{2}{*}{ Assigned bacterial spp. } & \multirow{2}{*}{$\begin{array}{l}\text { Sand fly } \\
\text { origin }\end{array}$} & \multicolumn{2}{|c|}{ Similarity \% } & \multirow[t]{2}{*}{ Phylum } & \multirow[t]{2}{*}{ Family } & \multirow{2}{*}{$\begin{array}{l}\text { GenBank } \\
\text { ID }\end{array}$} \\
\hline & & EzTaxa & $\mathrm{NCBI}$ & & & \\
\hline \multirow[t]{2}{*}{ Aeromonas sp. } & P. major & 99.9 & 100 & Proteobacteria & Aeromonadaceae & MF372627 \\
\hline & P. kandelakii & 99.9 & 100 & Proteobacteria & Aeromonadaceae & MF372629 \\
\hline \multirow[t]{2}{*}{ Staphylococcus equorum equorum } & P. major & 100 & 100 & Firmicutes & Staphylococcaceae & MF372605 \\
\hline & P. kandelakii & 100 & 100 & Firmicutes & Staphylococcaceae & MF372618 \\
\hline \multirow[t]{2}{*}{ Aeromonas jandaei } & P. major & 99.7 & 99 & Proteobacteria & Aeromonadaceae & MF372624 \\
\hline & P. halepensis & 99.4 & 99 & Proteobacteria & Aeromonadaceae & MF372620 \\
\hline \multirow[t]{2}{*}{ Staphylococcus xylosus } & P. major & 100 & 100 & Firmicutes & Staphylococcaceae & MF372602 \\
\hline & P. kandelakii & 99.8 & 100 & Firmicutes & Staphylococcaceae & MF372601 \\
\hline Bacillus cereus & P. major & 100 & 100 & Firmicutes & Bacillaceae & MF372604 \\
\hline \multirow[t]{2}{*}{ Bacillus nakamurai } & P. major & 99.9 & 100 & Firmicutes & Bacillaceae & MF372611 \\
\hline & P. kandelakii & 99.9 & 100 & Firmicutes & Bacillaceae & MF372607 \\
\hline Bacillus subtilis & P. major & 99.9 & 99 & Firmicutes & Bacillaceae & MF372612 \\
\hline \multirow[t]{2}{*}{ Pantoea agglomerans } & P. major & 100 & 100 & Proteobacteria & Enterobacteriaceae & MF372619 \\
\hline & P. kandelakii & 100 & 100 & Proteobacteria & Enterobacteriaceae & MF289172 \\
\hline \multirow[t]{3}{*}{ Ralstonia pickettii } & P. major & 99.6 & 99 & Proteobacteria & Ralstoniaceae & MF372616 \\
\hline & P. kandelakii & 99.8 & 99 & Proteobacteria & Ralstoniaceae & MF372617 \\
\hline & P. halepensis & 99.9 & 99 & Proteobacteria & Ralstoniaceae & MF372615 \\
\hline \multirow[t]{2}{*}{ Ralstonia mannitolilytica } & P. major & 99.8 & 99 & Proteobacteria & Ralstoniaceae & MF372614 \\
\hline & P. halepensis & 99.6 & 99 & Proteobacteria & Ralstoniaceae & MF372613 \\
\hline Staphylococcus argenteus & P. major & 99.7 & 99 & Firmicutes & Staphylococcaceae & MF372606 \\
\hline Ralstonia syzygii & P. major & 99.7 & 99 & Proteobacteria & Ralstoniaceae & MF372625 \\
\hline Staphylococcus succinus casei & P. kandelakii & 99.9 & 99 & Firmicutes & Staphylococcaceae & MF372608 \\
\hline Staphylococcus saprophyticus bovis & P. kandelakii & 100 & 99 & Firmicutes & Staphylococcaceae & MF372603 \\
\hline Curtobacterium plantarum & P. kandelakii & 100 & 100 & Proteobacteria & Enterobacteriaceae & MF372626 \\
\hline Staphylococcus saprophyticus saprophyticus & P. andelakii & 100 & 100 & Firmicutes & Staphylococcaceae & MF372628 \\
\hline Enterococcus casseliflavus & P. kandelakii & 100 & 99 & Firmicutes & Enterococcaceae & MF372609 \\
\hline Bacillus altitudinis & P. kandelakii & 99.8 & 99 & Firmicutes & Bacillaceae & MF372610 \\
\hline Aeromonas veronii & P. halepensis & 99.8 & 99 & Proteobacteria & Aeromonadaceae & MF372621 \\
\hline Aeromonas salmonicida achromogenes & P. halepensis & 99.8 & 99 & Proteobacteria & Aeromonadaceae & MF372622 \\
\hline Staphylococcus haemolyticus & P. halepensis & 98.8 & 99 & Firmicutes & Staphylococcaceae & MF372630 \\
\hline Aeromonas encheleia & P. halepensis & 99.9 & 100 & Proteobacteria & Aeromonadaceae & MF372631 \\
\hline Aeromonas rivuli & P. halepensis & 99.9 & 99 & Proteobacteria & Aeromonadaceae & MF372623 \\
\hline
\end{tabular}

[26, 41]. Proteobacteria and Firmicutes with 57.4 and $21.7 \%$, respectively, were predominant in 62 insect species. Yun et al. [42] showed that Proteobacteria with 62.1\% and Firmicutes with $20.7 \%$ were the predominant phyla in 218 species belong to 21 insect taxonomic orders. Results of the present study showed that 80,18 and $2 \%$ of the bacterial species were observed in a single, two and three sand fly species, respectively. This is similar to the results of previous studies demonstrating that most bacterial operational taxonomic units (OTUs) were restrained to a single environment [42, 43]. These species-specific compositions in gut microbiota of the sand flies can be explained by food sources of the insects at larval and adult stages and the environmental habitats in which they live. Food diet, comprising mostly sugar sources for adults and organic matters for larvae, play a major role in the microbiome community of sand flies. The lack of shared bacteria in the gut microbiota of the same sand fly species from two distinct regions (steppe and the mountainous) shows the great influence of environment on the community composition of insect gut microbiota. Interestingly, most bacteria in the mountainous region (five out of seven species) belonged to the family Enterobacteriaceae. In contrast, members of this 
Table 4 Details of the bacteria isolated from the midgut of sand flies captured in the mountainous region (Meshkinshahr) of northwestern Iran

\begin{tabular}{|c|c|c|c|c|c|c|}
\hline \multirow[t]{2}{*}{ Assigned bacterial spp. } & \multirow{2}{*}{$\begin{array}{l}\text { Sand fly } \\
\text { origin }\end{array}$} & \multicolumn{2}{|c|}{ Similarity \% } & \multirow[t]{2}{*}{ Phylum } & \multirow[t]{2}{*}{ Family } & \multirow{2}{*}{$\begin{array}{l}\text { GenBank } \\
\text { ID }\end{array}$} \\
\hline & & EzTaxa & $\mathrm{NCBI}$ & & & \\
\hline Kluyvera cryocrescens & P. kandelakii & 99.5 & 99 & Proteobacteria & Enterobacteriaceae & MF372632 \\
\hline Enterobacter aerogenes & P. kandelakii & 100 & 100 & Proteobacteria & Enterobacteriaceae & MF372633 \\
\hline Enterococcus faecium & P. kandelakii & 100 & 100 & Proteobacteria & Enterococcaceae & MF372634 \\
\hline Enterobacter ludwigii & P. kandelakii & 100 & 99 & Proteobacteria & Enterobacteriaceae & MF372638 \\
\hline Staphylococcus hominis & P. kandelakii & 99.9 & 100 & Firmicutes & Staphylococcaceae & MF372635 \\
\hline Klebsiella pneumoniae & P. major & 100 & 100 & Proteobacteria & Enterobacteriaceae & MF372637 \\
\hline Staphylococcus sciuri & P. major & 100 & 100 & Firmicutes & Staphylococcaceae & MF372636 \\
\hline
\end{tabular}

family had the lowest frequency in the steppe region. This finding is supported by previous studies indicating a significant positive correlation between the gut microbiota and environmental conditions such as temperature and precipitation in various insect species [31, 32, 41]. Similar to other insects, sand flies are ectothermic insects and temperature affects their biology and fitness parameters such as longevity, survival and behavior [12, 44]. In the steppe region of this study, the climate is warmer than that of the mountainous region, which might support the additional richness of bacteria in sand fly guts of that region.

When the microbial diversity of the VL vectors of this study were compared with data of sand flies from the Old World [26, 45, 46], we found some similar bacteria such as the genera Enterobacter and Staphylococcus and more specifically B. subtilis. Additionally, a low number of bacteria found in this study were common to those found in the phlebotomine sand flies from the Old and New World, namely B. subtilis, Staphylococcus spp., Enterobacter spp. and Klebsiella spp.

Sand fly larvae breed in soil where they feed on decaying organic matter. Soil characteristics and microbial community may affect the bacterial composition of the gut of sand fly larvae. Furthermore, they might cause regional changes in the bacterial communities observed in this study. A strong correlation between insect microbiota and environmental habitat, including soil, has already been reported for some ground insects such as $P$. argentipes [28], $P$. papatasi [26] and $P$. perniciosus [35].

Soil characteristics such as chemistry, moisture, temperature, agricultural activity and plant and animal species, noticeably affect soil bacterial diversity [41]. Soil characteristics and agricultural practices in the steppe

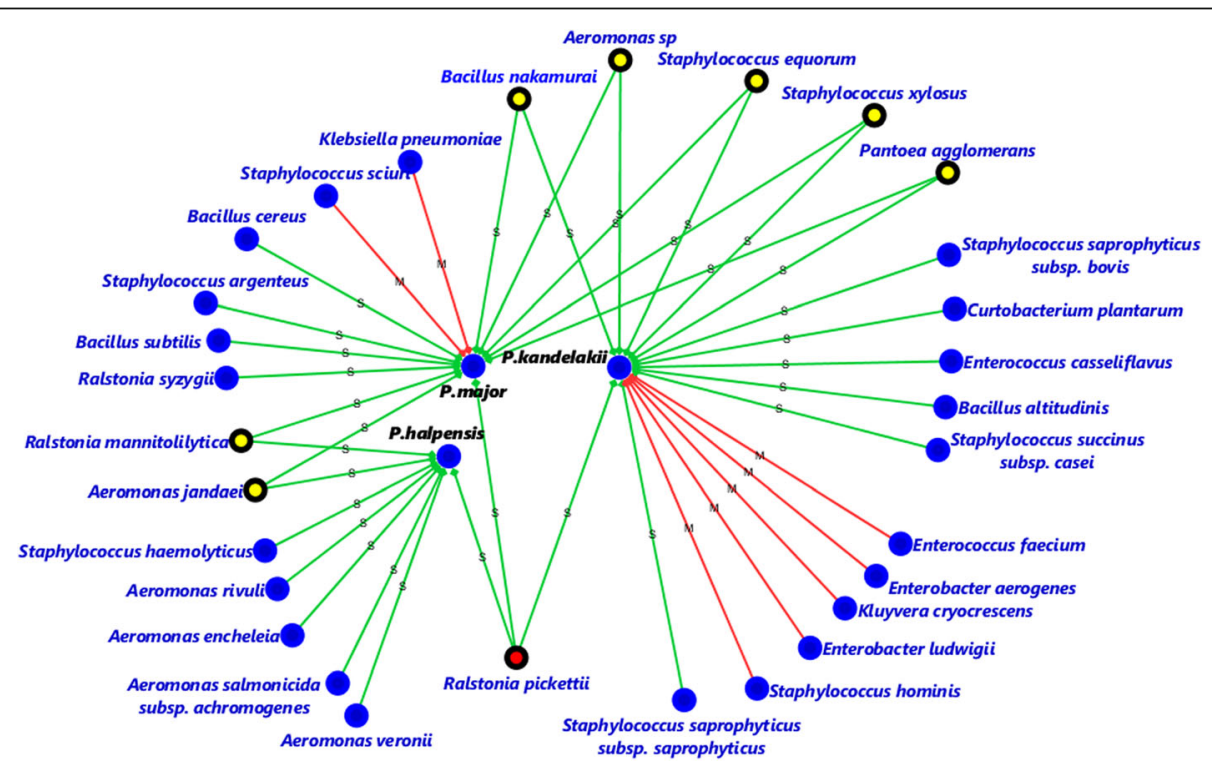

Fig. 3 Network analysis showing the shared and non-shared bacteria species isolated from $P$. kandelakii, $P$. major and $P$. halepensis (red squares). The bacteria species observed in three, two and one hosts can be identified by red, yellow (surrounded by black line) and blue circles, respectively. Red and green lines represent mountainous and steppe regions, respectively 


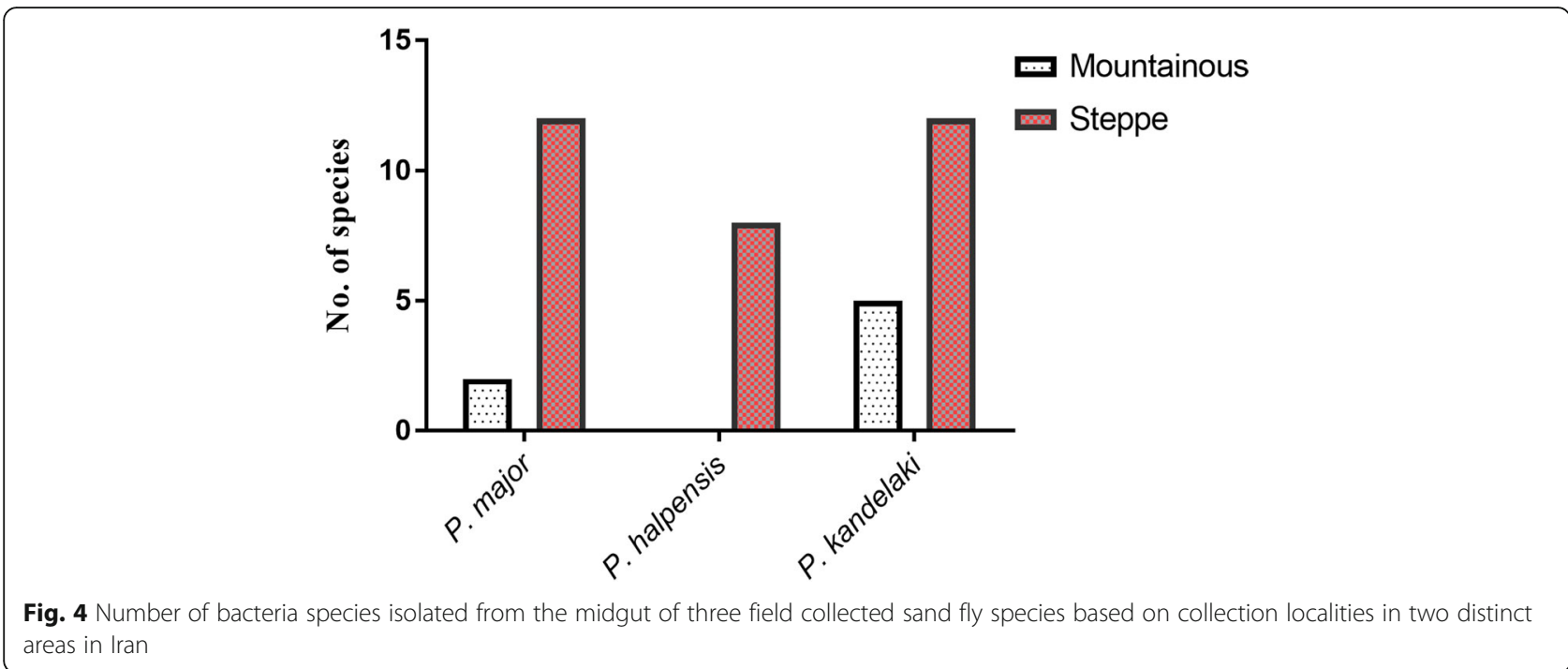

and mountainous areas of the present study were completely different; this might have affected the bacterial community structure in soil and resulted in the bacterial community variations. However, it is worth mentioning that only a few bacterial communities can pass transstadially from larval to adult stages [29].

Host physiological condition, gut morphology and food sources are important factors for insect microbial diversity $[36,42]$. Although no detailed information on the similarity of gut morphology and physicochemical conditions $(\mathrm{pH}$, oxygen availability, redox conditions and digestive enzyme) have been reported in P. kandelakii, $P$. major and $P$. halepensis, and remain still to be investigated, it seems that no significant differences exist between these characteristics in these close species. Therefore, diverse sources of bacteria might influence the gut microbiota of these three species with different habitats, behaviors and diets. Sand fly larvae are scavengers feeding on dead organic matter such as animal feces, bacteria, algae and fungi in sewage and organic sludge. In contrast, adult sand flies feed on flower nectar and plant sap, and adult female sand flies suck blood from humans, mammals and reptiles. Adult sand flies may acquire bacteria from plant sources and the skin of the hosts while sucking blood. Furthermore, bacteria may be transstadially transmitted from larval to adult midguts [16]. The microbiota of P. kandelakii, with 17 bacterial species, has the greatest richness among the three sand fly species. This may be because larvae or adults of this species consume more varied diets (therefore including more diverse bacterial species) than the other two species. Therefore, the higher level of bacterial richness could be associated with diets used; our study is thus similar to findings in previous studies showing that host diet seemed to affect the composition of gut microbiota in insects [42].

In this study we found Ralstonia pickettii as the only shared bacteria among all the three sand fly species in the steppe region. This species and other identified genera including Bacillus, Enterobacter, Enterococcus,

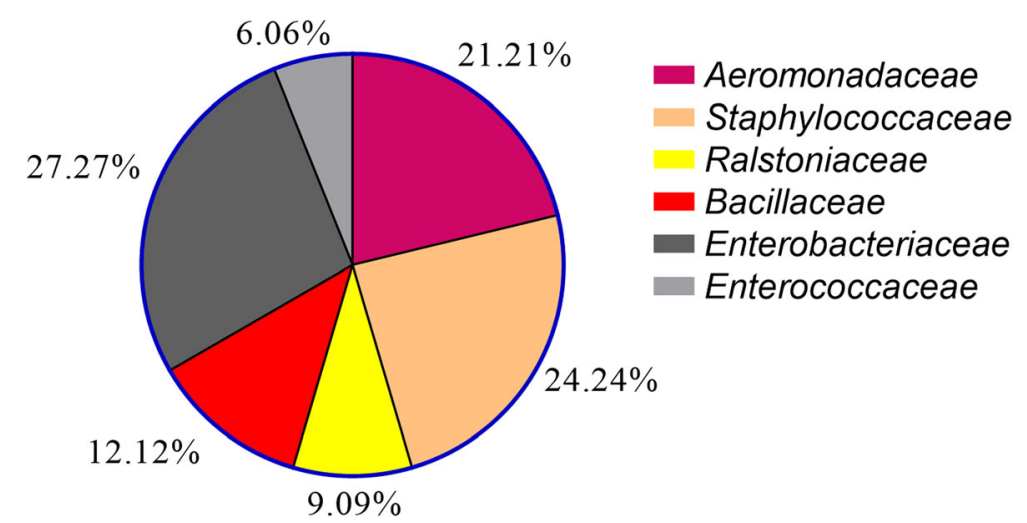

Fig. 5 Relative frequency of bacterial families isolated from the midgut of $P$. major, $P$. kandelakii and $P$. halepensis in the study areas of Iran 


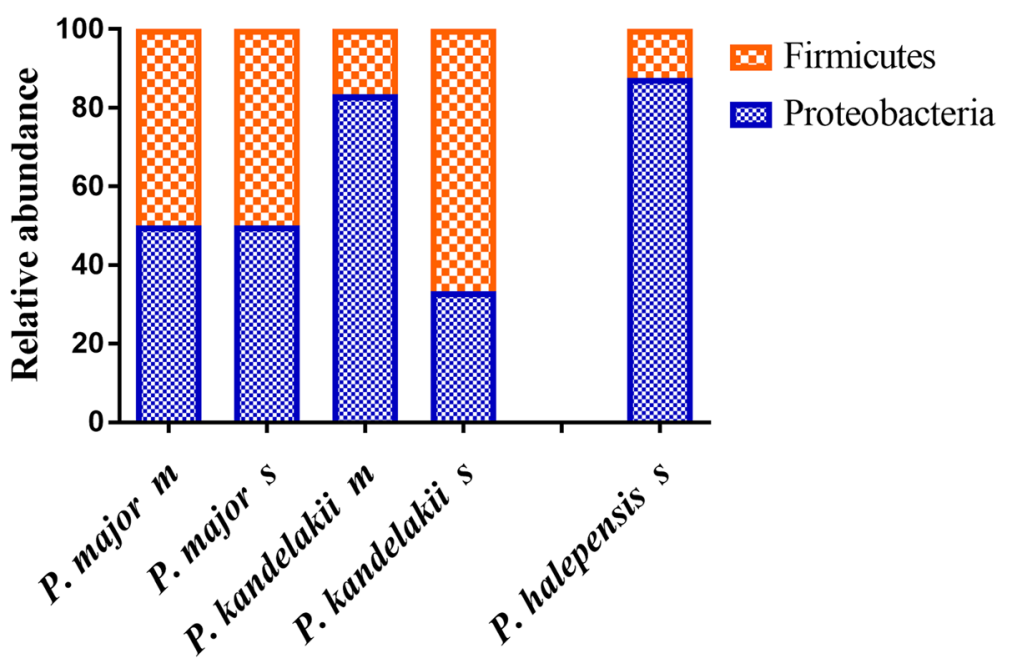

Fig. 6 Relative frequency of aerobic Proteobacteria and Firmicutes grown in BHI media from the gut of sand fly species originating from steppe $(\mathrm{s})$ and mountainous $(\mathrm{m})$ regions in northern Iran

Staphylococcus and Ralstonia are commonly related to plants common in the environments of Phlebotomus [26, 47]. Therefore, using plants visited by sand flies for sap consumption could be considered as a delivery method for introducing manipulated bacteria for a paratransgenesis approach [48].

Sand fly species of $P$. major and P. kandelakii are well known vectors of ZVL in Iran and other countries $[10,49-51]$ and $P$. halepensis is a susceptible vector of $L$. infantum in Georgia as well as $L$. major and $L$. tropica in other countries [52]. Phlebotomus kandelakii plays an important role in ZVL transmission in Iran and is suggested as the main vector of $\mathrm{ZVL}$ in both northeastern (steppe) and northwestern (mountainous) areas of the country [13]. Moreover, this species is a major vector of ZVL in other countries such as Georgia [53] and Turkey [54]. The high bacterial diversity in $P$. kandelakii could be linked to its vectorial capacity. A recent laboratory study on midgut microbiomes in Lutzomyia longipalpis, the major vector of VL in new world, suggests that the gut microbiota of the sand fly is an important factor for the replication and development of Leishmania spp. and parasite conversion to infective metacyclic promastigotes before transmission to a new host [55]. Furthermore, the study by Fraihi et al. [35] showed seasonal variations in microbiota composition of the midguts of female $P$. perniciosus with a species diversity decline to the end of the $L$. infantum transmission period. The influence of insect gut microbiota on vector capacity of mosquitoes and tsetse flies has also already been reported [56, 57]. Interestingly, in the present study, eight bacterial species $(27.27 \%)$ were linked to the family Enterobacteriaceae and detected in both steppe and mountainous regions and P. kandelakii and $P$. major. Members of this family have been reported in medically important insects [22, 24, $28,58,59]$ and involved in dietary supplementation, tolerance to environmental perturbations and maintenance and/or enhancement of host immune system homeostasis [57, 59-62]. Further investigations are needed to clarify possible relationships between these bacteria and the sand fly vector capacity for ZVL [55].

The detection of Bacillus subtilis and Pantoea agglomerans in sand flies studied here, suggests that these two bacterial species are potential candidates for the prevention of Leishmania transmission via paratransgenesis approaches [26, 35, 63, 64]. Pantoea agglomerans and B. subtilis have been used for the production of paratransgenic mosquitoes [65] and paratransgenic sand flies, respectively [16].

In this study we used a culture dependent-method and subsequently, differences in gut microbiota could be dissimilar from these resulting from the use of a culture independent-method. Culturing can potentially exclude slower-growing bacteria and those incapable of propagating on the test media; therefore, the diversity of the midgut microbiota still remains incomplete. Culture-independent approaches such as NGS provide a broader and deeper picture of gut microbiota diversity in host organisms [66]. However, we still need to search for cultivable bacteria present in insects because culturing bacteria still offers the best way of observing the diverse characteristics of the isolated organisms; the physiological characteristics such as antibiotic resistance, interspecies growth inhibition or population dynamics within vector cohorts of bacterial isolates can be determined. Also culturing facilitates bacterial genome sequencing, a further link towards revealing 
functionality [67], and availability of the candidate bacteria allows testing their malleability to accept foreign DNA (genes or plasmids).

Some of the limitations of the present study include a lack of next generation sequencing (NGS) facilities and not taking into account the age, sex, parity, gonotrophic cycle, blood meal, leishmanial infection and abdominal situation (gravid, semi gravid, empty) of the samples.

\section{Conclusions}

The present study has provided a detailed investigation of the composition and richness of the gut microbiota in three sand fly species from two ZVL foci with distinct geographical features using a culture-dependent method and sequencing of the $16 \mathrm{~S}$ rRNA gene. Furthermore, this study has shown differences between the taxonomic composition of bacteria that could be recovered in cultures from midguts of three different sand fly species isolated from steppe and mountainous regions. The study of sand fly microbiota is important due to the finding of given bacterial species on various sand fly species in different locations may lead to the development of paratransgenic approaches targeting multiple vectors in various localities to control the spread of leishmaniasis. Although there are a number of limitations, this study provides basic information on aerobic bacteria for a potential paratransgenesis strategy in the guts of insects and the associations of microbes and their hosts.

\section{Abbreviations}

NTD: Neglected tropical disease; L: Leishmania; ZVL: Zoonotic visceral leshmaniasis; P: Phlebotomus; VL: Visceral leishmaniasis; NGS: Next-generation sequencing; BHI: Brain heart infusion; OTUs: Operational taxonomic unit

\section{Acknowledgments}

The authors would like to thank Mrs Mohtarami for her valuable help and support in the laboratory.

\section{Funding}

This work has supported by Tehran University of Medical Sciences, Iran, grant number 28646.

\section{Availability of data and materials}

The data supporting the conclusions of this article are included within the article. The DNA sequences generated and/or analyzed during the present study were submitted to the GenBank database under the accession numbers MF289172 and MF372601-MF372638.

\section{Authors' contributions \\ FK, NMR and MAO designed the study. YR, HV, MM, MHS, MK and NC collected the samples, carried out the laboratory process and analyzed the results. FK and MAO wrote the draft of the manuscript. FK and YR participated in the species designation of sand flies. FK and MAO performed statistical analysis. MAO supervised the project and finalized the manuscript. All authors read and approved the final manuscript.}

Ethics approval and consent to participate Not applicable.

\section{Consent for publication}

Not applicable.

\section{Competing interests}

The authors declare that they have no competing interests.

\section{Publisher's Note}

Springer Nature remains neutral with regard to jurisdictional claims in published maps and institutional affiliations.

\section{Author details}

1Department of Medical Entomology and Vector Control, School of Public Health, Tehran University of Medical Sciences (TUMS), Tehran, Iran. ${ }^{2}$ Department of Parasitology, Pasteur Institute of Iran, Tehran, Iran.

${ }^{3}$ Department of Medical Parasitology and Mycology, School of Public Health, Tehran University of Medical Sciences, Tehran, Iran. ${ }^{4}$ Department of Pathobiology, School of Public Health, Tehran University of Medical Sciences, Tehran, Iran.

Received: 21 August 2018 Accepted: 19 December 2018

Published online: 07 January 2019

References

1. Akhoundi M, Kuhls K, Cannet A, Votýpka J, Marty P, Delaunay P, et al. A historical overview of the classification, evolution, and dispersion of Leishmania parasites and sandflies. PLoS Negl Trop Dis. 2016;10:e0004349.

2. Guernaoui S, Garcia D, Gazanion E, Ouhdouch Y, Boumezzough A, Pesson B, et al. Bacterial flora as indicated by PCR-temperature gradient gel electrophoresis (TGGE) of 165 rDNA gene fragments from isolated guts of phlebotomine sand flies (Diptera: Psychodidae). J Vector Ecol. 2011;36(Suppl. 1):144-7.

3. Alvar J, Vélez ID, Bern C, Herrero M, Desjeux P, Cano J, et al. Leishmaniasis worldwide and global estimates of its incidence. PLoS One. 2012;7:e35671.

4. Mohebali M. Visceral leishmaniasis in Iran: review of the epidemiological and clinical features. Iran J Parasitol. 2013;8:348.

5. Mohebali M, Hamzavi Y, Edrissian GH, Forouzani A. Seroepidemiological study of visceral leishmaniasis among humans and animal reservoirs in Bushehr Province, Islamic Republic of Iran. East Mediterr Health J. 2001; 7:912-7.

6. Nadim A. Epidemiology of Kala-azar in Iran. In: Nadim A, Javadian E, Momeni A, editors. Leishmania parasite and leishmaniasis. Tehran: University Press; 2008. p. 241-249 (In Persian).

7. Hajjaran H, Mohebali M, Mamishi S, Vasigheh F, Oshaghi MA, Naddaf SR, et al. Molecular identification and polymorphism determination of cutaneous and visceral leishmaniasis agents isolated from human and animal hosts in Iran. Biomed Res Int. 2013;2013:789326.

8. Rashti MS, Sahabi Z, Notash AK. Phlebotomus (Larroussius) keshishiani Hchurenkova 1936, another vector of visceral leishmaniasis in Iran. Iran J Public Health. 1995:24:25-30.

9. Azizi K, Rassi Y, Javadian E, Motazedian M, Rafizadeh S, Yaghoobi Ershadi M, et al. Phlebotomus (Paraphlebotomus) alexandri: a probable vector of Leishmania infantum in Iran. Ann Trop Med Parasitol. 2006;100:63-8.

10. Azizi K, Rassi Y, Javadian E, Motazedian M, Asgari Q, Yaghoobi-Ershadi M. First detection of Leishmania infantum in Phlebotomus (Larroussius) major (Diptera: Psychodidae) from Iran. J Med Entomol. 2008;45:726-31.

11. Oshaghi MA, Ravasan NM, Hide M, Javadian E-A, Rassi Y, Sadraei J, et al. Phlebotomus perfiliewi transcaucasicus is circulating both Leishmania donovani and L. infantum in northwest Iran. Exp Parasitol. 2009;123:218-25.

12. Oshaghi MA, Ravasan NM, Javadian E-A, Mohebali M, Hajjaran H, Zare Z, et al. Vector incrimination of sand flies in the most important visceral leishmaniasis focus in Iran. Am J Trop Med Hyg. 2009;81:572-7.

13. Rassi Y, Abai M, Oshaghi M, Javadian E, Sanei A, Rafidzadeh S, et al. First detection of Leishmania infantum in Phlebotomus kandelakii using molecular methods in north-eastern Islamic Republic of Iran. East Mediterr Health J. 2012;18:387

14. Seblova V, Oury B, Eddaikra N, Aït-Oudhia K, Pratlong F, Gazanion E, et al. Transmission potential of antimony-resistant Leishmania field isolates. Antimicrob Agents Chemother. 2014;58:6273-6.

15. Coutinho-Abreu IV, Zhu KY, Ramalho-Ortigao M. Transgenesis and paratransgenesis to control insect-borne diseases: current status and future challenges. Parasitol Int. 2010;59:1-8.

16. Hurwitz I, Hillesland H, Fieck A, Das P, Durvasula R. The paratransgenic sand fly: a platform for control of Leishmania transmission. Parasit Vectors. 2011;4:82. 
17. Wang S, Dos-Santos AL, Huang W, Liu KC, Oshaghi MA, Wei G, et al. Driving mosquito refractoriness to Plasmodium falciparum with engineered symbiotic bacteria. Science. 2017;357:1399-402.

18. Favia G, Ricci I, Marzorati M, Negri I, Alma A, Sacchi L, et al. Bacteria of the genus Asaia: a potential paratransgenic weapon against malaria. In: Aksoy S, editor. Transgenesis and the management of vector-borne disease, vol. 627. New York: Springer; 2008. p. 49-59.

19. Durvasula RV, Gumbs A, Panackal A, Kruglov O, Aksoy S, Merrifield RB, et al. Prevention of insect-borne disease: an approach using transgenic symbiotic bacteria. Proc Natl Acad Sci USA. 1997:94:3274-8.

20. Medlock J, Atkins KE, Thomas DN, Aksoy S, Galvani AP. Evaluating paratransgenesis as a potential control strategy for African trypanosomiasis. PLoS Negl Trop Dis. 2013;7:e2374.

21. Chavshin AR, Oshaghi MA, Vatandoost H, Pourmand MR, Raeisi A, Enayati $A A$, et al. Identification of bacterial microflora in the midgut of the larvae and adult of wild caught Anopheles stephensi: a step toward finding suitable paratransgenesis candidates. Acta Trop. 2012;121:129-34.

22. Chavshin AR, Oshaghi MA, Vatandoost H, Pourmand MR, Raeisi A, Terenius O. Isolation and identification of culturable bacteria from wild Anopheles culicifacies, a first step in a paratransgenesis approach. Parasit Vectors. 2014; 7:419.

23. Chavshin AR, Oshaghi MA, Vatandoost H, Yakhchali B, Raeisi A, Zarenejad F. Escherichia coli expressing a green fluorescent protein (GFP) in Anopheles stephensi: a preliminary model for paratransgenesis. Symbiosis. 2013;60:17-24.

24. Favia G, Ricci I, Damiani C, Raddadi N, Crotti E, Marzorati M, et al. Bacteria of the genus Asaia stably associate with Anopheles stephensi, an Asian malarial mosquito vector. Proc Natl Acad Sci USA. 2007;104:9047-51.

25. Akbari S, Oshaghi MA, Hashemi-Aghdam SS, Hajikhani S, Oshaghi G, Shirazi $\mathrm{MH}$. Aerobic bacterial community of american cockroach Periplaneta americana, a step toward finding suitable paratransgenesis candidates. J Arthropod Borne Dis. 2015;9:35

26. Maleki-Ravasan N, Oshaghi MA, Afshar D, Arandian MH, Hajikhani S, Akhavan $A A$, et al. Aerobic bacterial flora of biotic and abiotic compartments of a hyperendemic zoonotic cutaneous leishmaniasis ( $\mathrm{ZCL})$ focus. Parasit Vectors. 2015:8:63.

27. Maleki-Ravasan N, Oshaghi MA, Hajikhani S, Saeidi Z, Akhavan AA, GeramiShoar $\mathrm{M}$, et al. Aerobic microbial community of insectary population of Phlebotomus papatasi. J Arthropod Borne Dis. 2014;8:69.

28. Hillesland H, Read A, Subhadra B, Hurwitz I, McKelvey R, Ghosh K, et al. Identification of aerobic gut bacteria from the kala azar vector, Phlebotomus argentipes: a platform for potential paratransgenic manipulation of sand flies. Am J Trop Med Hyg. 2008;79:881-6.

29. Peterkova-Koci K, Robles-Murguia M, Ramalho-Ortigao M, Zurek L. Significance of bacteria in oviposition and larval development of the sand fly Lutzomyia longipalpis. Parasit Vectors. 2012;51:145.

30. Koch $\mathrm{H}$, Schmid-Hempel P. Bacterial communities in central European bumblebees: low diversity and high specificity. Microb Ecol. 2011;62:121-33.

31. Zouache K, Raharimalala FN, Raquin V, Tran-Van V, Raveloson LHR, Ravelonandro P, et al. Bacterial diversity of field-caught mosquitoes, Aedes albopictus and Aedes aegypti, from different geographic regions of Madagascar. FEMS Microbiol Ecol. 2010;75:377-89.

32. Behar A, Yuval B, Jurkevitch E. Community structure of the Mediterranean fruit fly microbiota: seasonal and spatial sources of variation. Isr J Ecol Evol. 2008;54:181-91.

33. Osei-Poku J, Mbogo C, Palmer W, Jiggins F. Deep sequencing reveals extensive variation in the gut microbiota of wild mosquitoes from Kenya. Mol Ecol. 2012;21:5138-50.

34. Hegde S, Rasgon JL, Hughes GL. The microbiome modulates arbovirus transmission in mosquitoes. Curr Opin Virol. 2015;15:97-102.

35. Fraihi W, Fares W, Perrin P, Dorkeld F, Sereno D, Barhoumi W, et al. An integrated overview of the midgut bacterial flora composition of Phlebotomus perniciosus, a vector of zoonotic visceral leishmaniasis in the Western Mediterranean Basin. Negl Trop Dis. 2017:11:e0005484.

36. Arzamani K. Visceral leishmaniasis in North Khorasan Province, north east of Iran. Int J Infect Dis. 2012;16:e340

37. Weisburg WG, Barns SM, Pelletier DA, Lane DJ. 165 ribosomal DNA amplification for phylogenetic study. J Bacteriol. 1991;173:697-703.

38. Chun J, Lee J-H, Jung Y, Kim M, Kim S, Kim BK, et al. EzTaxon: a web-based tool for the identification of prokaryotes based on 165 ribosomal RNA gene sequences. Int J Syst Evol Microbiol. 2007;57:2259-61.
39. Devulder G, Perriere G, Baty F, Flandrois J. BIBI, a bioinformatics bacterial identification tool. J Clin Microbiol. 2003:41:1785-7.

40. Shannon P, Markiel A, Ozier O, Baliga NS, Wang JT, Ramage D, et al. Cytoscape: a software environment for integrated models of biomolecular interaction networks. Genome Res. 2003;13:2498-504.

41. Huang S, Zhang $\mathrm{H}$. The impact of environmental heterogeneity and life stage on the hindgut microbiota of Holotrichia parallela larvae (Coleoptera: Scarabaeidae). PLoS One. 2013;8:e57169.

42. Yun J-H, Roh SW, Whon TW, Jung M-J, Kim M-S, Park D-S, et al. Insect gut bacterial diversity determined by environmental habitat, diet, developmental stage, and phylogeny of host. Appl Environ Microbiol. 2014; 80:5254-64.

43. Nemergut DR, Costello EK, Hamady M, Lozupone C, Jiang L, Schmidt SK, et al. Global patterns in the biogeography of bacterial taxa. Environ Microbiol. 2011;13:135-44.

44. Oshaghi M, Ravasan NM, Javadian E, Rassi Y, Sadraei J, Enayati A, et al. Application of predictive degree day model for field development of sandfly vectors of visceral leishmaniasis in northwest of Iran. J Vector Borne Dis. 2009;46:247.

45. Mukhopadhyay J, Braig HR, Rowton ED, Ghosh K. Naturally occurring culturable aerobic gut flora of adult Phlebotomus papatasi, vector of Leishmania major in the Old World. PLoS One. 2012;7:e35748.

46. Akhoundi M, Bakhtiari R, Guillard T, Baghaei A, Tolouei R, Sereno D, et al. Diversity of the bacterial and fungal microflora from the midgut and cuticle of phlebotomine sand flies collected in north-western Iran. PLoS One. 2012; 7:e50259.

47. Dillon $\mathrm{R}$, Kordy EE, Shehata M, Lane $\mathrm{R}$. The prevalence of a microbiota in the digestive tract of Phlebotomus papatasi. Ann Trop Med Parasitol. 1996;90: 669-73.

48. Müller G, Schlein Y. Nectar and honeydew feeding of Phlebotomus papatasi in a focus of Leishmania major in Neot Hakikar oasis. J Vector Ecol. 2004;29:154-8.

49. Guan L-R, Zhou Z-B, Jin C-F, Fu Q, Chai J-J. Phlebotomine sand flies (Diptera: Psychodidae) transmitting visceral leishmaniasis and their geographical distribution in China: a review. Infect Dis Poverty. 2016;5:15.

50. Ok Ü, Balcıoğlu I, Özkan AT, Özensoy S, Özbel Y. Leishmaniasis in Turkey. Acta Trop. 2002:84:43-8.

51. Nadim A, Javadian E, Tahvildar-Bidruni G, Mottaghi M. Epidemiological aspects of kala-azar in Meshkin shar, Iran: investigation on vectors. Iran J Public Health. 1992;21:61-72.

52. Sadlova J, Hajmova M, Volf P. Phlebotomus (Adlerius) halepensis vector competence for Leishmania major and Le. tropica. Med Vet Entomol. 2003; 17:244-50.

53. Giorgobiani E, Lawyer PG, Babuadze G, Dolidze N, Jochim RC, Tskhvaradze L, et al. Incrimination of Phlebotomus kandelakii and Phlebotomus balcanicus as vectors of Leishmania infantum in Tbilisi, Georgia. PLoS Negl Trop Dis. 2012; 6:e1609.

54. Sari B, Limoncu ME, Balcioglu IC, Aldemir A, Tasci GT, Kiliç Y, et al. Seroepidemiological and entomological survey in a new focus of zoonotic visceral leishmaniasis in Kars Province, northeastern Turkey. Vet Parasitol. 2015;209:179-87.

55. Kelly PH, Bahr SM, Serafim TD, Ajami NJ, Petrosino JF, Meneses C, et al. The gut microbiome of the vector Lutzomyia longipalpis is essential for survival of Leishmania infantum. mBio. 2017:8:e01121-16.

56. Pais R, Lohs C, Wu Y, Wang J, Aksoy S. The obligate mutualist Wigglesworthia glossinidia influences reproduction, digestion, and immunity processes of its host, the tsetse fly. Appl Environ Microbiol. 2008;74:5965-74.

57. Weiss B, Aksoy S. Microbiome influences on insect host vector competence. Trends Parasitol. 2011;27:514-22.

58. Chavshin AR, Oshaghi MA, Vatandoost H, Yakhchali B, Zarenejad F, Terenius O. Malpighian tubules are important determinants of Pseudomonas transstadial transmission and longtime persistence in Anopheles stephensi. Parasit Vectors. 2015:8:36.

59. Lindh JM, Terenius O, Faye I. 165 rRNA gene-based identification of midgut bacteria from field-caught Anopheles gambiae sensu lato and A. funestus mosquitoes reveals new species related to known insect symbionts. Appl Environ Microbiol. 2005;71:7217-23.

60. Dong Y, Manfredini F, Dimopoulos G. Implication of the mosquito midgut microbiota in the defense against malaria parasites. PLoS Pathog. 2009;5: e1000423.

61. Xi Z, Ramirez JL, Dimopoulos G. The Aedes aegypti toll pathway controls dengue virus infection. PLoS Pathog. 2008:4:e1000098. 
62. Pumpuni C, Beier M, Nataro J, Guers LD, Davis J. Plasmodium falciparum: inhibition of sporogonic development in Anopheles stephensi by gramnegative bacteria. Exp Parasitol. 1993;77:195-9.

63. Dutkiewicz J, Mackiewicz B, Lemieszek MK, Golec M, Milanowski J. Pantoed agglomerans: a mysterious bacterium of evil and good. Part I. Deleterious effects: dust-borne endotoxins and allergens - focus on cotton dust. Ann Agric Environ Med. 2015;22:576-88.

64. Heerman M, Weng J-L, Hurwitz I, Durvasula R, Ramalho-Ortigao M. Bacterial infection and immune responses in Lutzomyia longipalpis sand fly larvae midgut. PLoS Negl Trop Dis. 2015;9:e0003923.

65. Wang S, Ghosh AK, Bongio N, Stebbings KA, Lampe DJ, Jacobs-Lorena M. Fighting malaria with engineered symbiotic bacteria from vector mosquitoes. Proc Natl Acad Sci USA. 2012;109:12734-9.

66. Fukatsu T. Next-generation sequencing sheds light on intricate regulation of insect gut microbiota. Mol Ecol. 2012;21:5908-10.

67. Moro CV, Tran FH, Raharimalala FN, Ravelonandro P, Mavingui P. Diversity of culturable bacteria including Pantoea in wild mosquito Aedes albopictus. BMC Microbiol. 2013;13:70.

Ready to submit your research? Choose BMC and benefit from:

- fast, convenient online submission

- thorough peer review by experienced researchers in your field

- rapid publication on acceptance

- support for research data, including large and complex data types

- gold Open Access which fosters wider collaboration and increased citations

- maximum visibility for your research: over $100 \mathrm{M}$ website views per year

At $\mathrm{BMC}$, research is always in progress.

Learn more biomedcentral.com/submissions 